Running head: VOICE MOTOR LEARNING AND PRACTICE VARIABILITY

\title{
Effects of Practice Variability on Learning of Relaxed Phonation in Vocally Hyperfunctional Speakers
}

\author{
Amy Y.-H. WONG \\ Estella P.-M. MA \\ $\&$ \\ Edwin M.-L. YIU \\ Voice Research Laboratory, Division of Speech and Hearing Sciences \\ The University of Hong Kong
}

[Presented at the American Speech-Language-Hearing-Association (ASHA) Convention, November 2008, Chicago, Iowa]

\section{Address for correspondence:}

Estella Ma, Ph.D. Assistant Professor, Voice Research Laboratory, Division of Speech and Hearing Sciences, The University of Hong Kong, 5/F Prince Philip Dental Hospital, 34 Hospital Road, Hong Kong

Telephone: (852) 28590594 Fax: (852) 25590060 Email: estella.ma@,hku.hk 


\begin{abstract}
The present study investigated the effects of practice variability on the learning of relaxed phonation using a motor learning perspective. Twenty one individuals with hyperfunctional voice problems were evenly and randomly assigned to three groups of practice conditions: constant, blocked, and random practice conditions. During training, participants in the constant practice condition were asked to read aloud sentence stimuli with four Chinese characters. Participants in the blocked practice condition were asked to read aloud sentence stimuli with increasing sentence length, starting from sets of two characters to five characters. Participants in the random practice condition were asked to practice reading sentence stimuli of variable length from two to five characters presented in a random fashion. Surface electromyographic feedback (sEMG) from the thyrohyoid muscle site was given to each participant after reading every two sentence stimuli. Results demonstrated that for all participants, voice motor learning was evidenced by the decreased sEMG levels in delayed retention test. Generalization to untrained passage was shown as well. However, results did not reveal any difference in the learning among the three practice conditions. The findings from the present study did not support the hypothesis of contextual interference, which states that practice using variable items presented in a random mode is more beneficial to learning than practice using constant items.
\end{abstract}

Keywords: variable practice, voice motor learning, dysphonia, contextual interference, surface electromyography (EMG) 


\section{INTRODUCTION}

Hyperfunctional voice disorders can be characterized by the use of excessive laryngeal muscle tension during phonation ${ }^{1}$. Voice training that aims at reducing muscle tension in perilaryngeal area during phonation (or, relaxed phonation) has been widely accepted as an effective approach for treating hyperfunctional voice disorder ${ }^{2}$. During the voice training, motor learning is involved as dysphonic individuals learn new skills in adjusting and coordinating their phonatory organs through practice so that they can phonate effectively with minimal effort ${ }^{3}$. Motor learning is defined as a set of processes that results in relative permanent changes in movement capabilities after practice or experience ${ }^{4}$. Therefore, learning should be assessed using long-term follow-up performance rather than performance during training. Long-term follow-up performance can be evaluated using retention tests and generalization transfer tests with novel, untrained stimuli.

The literature has documented different learning parameters that can affect how individuals learn a motor skill. One of these parameters is practice variability. It refers to the different variety of movements and context characteristics the learner experiences when practicing a motor skill ${ }^{5}$. It is argued that practicing a motor skill under various conditions can provide learners with a wider range of movement experiences ${ }^{6}$. Three practice conditions have been frequently used in the motor learning literature. They are constant, blocked and random practice. Constant practice involves practicing a motor skill under one condition ${ }^{7}$. Blocked practice involves practicing a skill under different conditions which are arranged in a fixed sequence ${ }^{6}$. Random practice involves practicing 
a skill under different conditions. Unlike blocked practice, the conditions in random practice are arranged in a random order ${ }^{7}$.

Contextual interference has been used to explain the effects of practice variability on motor learning. Contextual interference refers to the disruption effects on motor performance and motor learning that are caused by various practice conditions of a motor task. Practice under conditions with high contextual interference (as in random practice condition) results in better retention and transfer performance than practice under conditions with low contextual interference (as in constant practice condition). Currently, there are two different hypotheses proposed to account for the type of cognitive processing that contributes to the effects of contextual interference: Elaboration Hypothesis ${ }^{8}$ and Forgetting and Reconstruction Hypothesis ${ }^{9}$. Shea and Morgan ${ }^{8}$ first put forward the Elaboration Hypothesis. It suggests that practice under variable conditions arranged in a random fashion provides learner with the opportunities to compare and contrast the variations of the motor learning skills. This comparison and contrast process facilitates the learner to develop richer mental representations of the motor skills and establish more distinct memories than those in constant and blocked practice conditions. As a result, the comparison process during random practice conditions promotes retention and transfer. On the contrary, constant and blocked practice conditions allow individuals to bypass the comparison process due to the repetitive nature of the task. Therefore, the omission of the comparison process leads to better performance of motor skills during acquisition phase in constant and blocked practice conditions but the retention and transfer tests that require individuals to undergo more comparisons fail to show such improvement. 
Lee and Magill ${ }^{9}$ proposed another hypothesis called the Forgetting and Reconstruction Hypothesis to explain the effects of practice variability. This hypothesis states that while learning a motor skill, the learner is required to temporarily forget the previous motor trial from the working memory so that the following trials can be planned, reconstructed and executed effectively. Blocked practice condition omits the 'forget and reconstruct' process, which enables the learner to remember the previous motor learning skills and the movement is maintained in the working memory across the block of practice trials. Therefore, blocked practice condition promotes good performance in acquisition. In contrast, random practice condition involves practicing different motor trials, which are arranged in a random sequence, which constantly requires the learner to undergo the 'forgetting and reconstruction' process. As practice proceeds, continuous reconstruction skills have been developed through a trial-to-trial basis, and such reconstruction skills facilitate good performance in retention and transfer.

In the field of sport sciences, there have been a number of studies that investigated the effects of contextual interference on motor learning. Shea and Morgan ${ }^{8}$ compared two groups of participants' response time in a tennis ball grasping task, with each group engaging in either a blocked or a random practice condition. Each participant was required to perform three tasks in the acquisition phase and each of tasks required the participants to perform the following actions as quickly as possible: 1) release a start button following either a blue, red or white stimulus light for each of the task; 2) grasp the tennis ball and 3) use the tennis ball to knock down three freely moveable, designated barriers in a predetermined order (i.e., knocking the barriers at the right rear, left middle and right front for the first task; right front, left middle and right rear for the second task; 
and left front, right middle and left rear for the final task). Each participant was required to undergo 18 practice trials for each task, so that a total of 54 trials were accomplished. The participants in the blocked practice group completed the first task before practicing the second and the third tasks while the participants in the random practice group practiced the three tasks which were arranged in a random fashion. The results showed that participants who underwent blocked practice condition showed significantly faster responses (i.e., better performance) during acquisition phase than those who underwent random practice condition. However, participants who practiced using random practice conditions showed significantly faster responses during retention and transfer sessions.

In the area of communication disorders, Knock and colleagues ${ }^{10}$ found that random practice conditions facilitated relearning of speech production skills in individuals with acquired apraxia of speech than blocked practice conditions. Recently, attempts have also been carried out to investigate how contextual interference affects motor learning in the voice area. $\mathrm{Yu}^{11}$ studied how practice variability contributed to motor learning of relaxed phonation in a group of vocally healthy individuals. The participants were randomly assigned to two groups. Participants in group one were required to read the sentence stimuli presented in a random order (random group) while participants in the other group were given blocks of sentence stimuli to read (blocked group). Her study did not reveal any significant effects of practice variability between the two groups. However, vocally healthy individuals were employed in her study and whether these findings can be generalized to the dysphonic individuals remains to be evaluated. It is possible that dysphonic individuals may show a different attention focus during motor learning practice when compared to vocally healthy individuals. It would be interesting to further 
investigate the effects of practice variability on learning relaxed phonation task in dysphonic individuals to evaluate if there is a generalization of results to the pathological group.

In the present study, surface electromyography (sEMG) was used as a voice training tool to provide augmented feedback for dysphonic participants to reduce muscle tensions during phonation. The literature has documented the use of sEMG feedback in reducing excessive muscle tensions in laryngeal area for patients with vocal nodules. In the study by Stemple, Weiler, Whitehead and Komray ${ }^{12}$, participants with vocal nodules were observed to reduce their laryngeal muscle tension levels significantly after undertaking eight sessions of sEMG biofeedback training. Andrews and her colleagues also documented that sEMG could be used as an effective visual feedback tool to treat hyperfunctional dysphonia ${ }^{13}$. Similar achievement was described in a case study by Allen, Bernstein and Chait ${ }^{14}$, which provided sEMG biofeedback to a 9-year-old young boy with hyperfunctional dysphonia associated with vocal nodules and the use of such visual feedback was able to help the boy reduce laryngeal muscle tension during phonation. In view of these promising results brought by the use of sEMG in voice therapy, the present study will make use of this instrument as augmented feedback during the relaxed phonation training and as outcome measures of the training.

The aim of the present study was to investigate the effects of practice variability on the learning of relaxed phonation in individuals with hyperfunctional dysphonia. It was hypothesized that the participants receiving random practice condition would demonstrate 
better motor learning on relaxed phonation when compared to participants receiving blocked practice and constant practice conditions.

\section{METHODS}

\section{$\underline{\text { Participants }}$}

Twenty-one dysphonic individuals ( 18 females and 3 males; mean age $=26.71$ years, $\mathrm{SD}=8.50$, range $=19$ to 48 years) participated in the present study. All participants 1) could read and speak Cantonese fluently; 2) had been suffering from voice problems and laryngeal discomfort for the past three consecutive weeks prior to the study; and 3) did not receive any prior voice training or have experience in using surface electromyography (sEMG) prior to the present study. Participants were excluded from the present study if they 1) failed the hearing screening tested at 30dB HL for octave frequencies between 2 $\mathrm{kHz}$ and $8 \mathrm{kHz} ; 2$ ) had a previous history of, or present with a respiratory disorder and allergy; or 3) had a previous history of, or present with any form of neurological speech and language disorders.

\section{Experimental set-up}

Surface electromyography (sEMG) system (AD Instrument PowerLab Unit, model ML 780 with an eight-channels and Dual Bio Amp model ML 135) and silver/silver chloride electrodes with $10 \mathrm{~mm}$ in diameter were used in the study. The sEMG system was connected to a Labview-based training system on relaxed phonation ${ }^{15}$ (Figure 1). The training system captured, processed and analyzed the sEMG signals in real time. Throughout the training, vocal intensity levels were monitored to ensure the participants maintained similar range of intensity levels during phonation. 


\section{$\underline{\text { Put Figure } 1 \text { here }}$}

Each participant took part individually in the study. Abrasive scrub was applied onto the participant's orofacial and thyrohyoid site to prepare for sEMG electrode attachment. Surface electrodes with electrolyte gel for reducing impedance at the sites of contacts were used. In the present study, the orofacial site and thyrohyoid site were used as they could capture relatively stable sEMG signals ${ }^{16}$. A pair of electrodes was placed over thyrohyoid area, each being $0.5 \mathrm{~cm}$ away from the midline of thyrohyoid membrane. Another pair of electrodes was placed on the orofacial site, each being $1 \mathrm{~cm}$ away from the lip corner on each side of the face. A dry earth strap was wrapped firmly around each participant's wrist. After the electrodes and the dry earth strap were secured in place, the participants were asked to rotate their heads to ensure no movement artifact was shown in the sEMG recordings.

\section{$\underline{\text { Training stimuli }}$}

Three sets of training stimuli were prepared (Appendix 1a, 1b and 1c). Each training list contained 24 Chinese characters as target characters, which was adapted from the word lists used by Yiu et al. ${ }^{16}$. They covered all sounds ( 19 consonants, 8 vowels, 10 diphthongs) and six lexical tones in Cantonese. The target characters were selected from the 750 most frequently occurring Chinese characters in Hong Kong ${ }^{17}$ (Table 1). The first set of training stimuli comprised 24 target characters, each was embedded in the Cantonese carrier phrase $/ \mathrm{ji}_{55} \mathrm{k}_{33} \mathrm{hei}_{22}$ (target character) / [meaning 'this one is (target character)'] to form a sentence stimulus (Appendix 1a). The second set of training stimuli 
consisted of sentences of increasing sentence length starting from sets of two characters to five characters across the training blocks (Appendix 1b). The third set of training stimuli comprised of all 24 target characters embedded in variable lengths of phrases being presented in a random fashion (Appendix 1c). The training stimuli were used in baseline, training and retention testing.

\section{Put Table 1 here}

\section{Procedures}

Pre-training baseline (session 1). Pre-training baseline was collected in the first session. The World Health Organization's International Classification of Functioning, Disability and Health (ICF) ${ }^{18}$ was adopted to evaluate voice training outcomes holistically from impairment and functional perspectives ${ }^{19}$. Impairment level was evaluated by the root-mean-square values of sEMG signals collected from participants. Participants were required to read aloud four blocks of training stimuli (24 sentences per block). They were also required to read aloud the Cantonese passage "North Wind and the Sun" at their most comfortable pitch and loudness. At this pre-training baseline, no sEMG feedback was given to the participants on their performance. The sEMG signals at both the orofacial and thyrohyoid sites were recorded for each sentence stimulus for analysis purpose. The activity and participation levels of the participants due to the voice problems were also evaluated. Each participant was asked to complete the Voice Activity and Participation Profile (VAPP) ${ }^{20}$. The VAPP is a questionnaire that assesses the participants' perception on how voice disorders affect their quality of life in job, daily communication, social communication and emotion domains. 
Training sessions (session 2 - 9). After the pre-training baseline session, the participants were required to engage in a four-week relaxed phonation training, with two sessions per week. Participants were equally and randomly assigned to one of the three practice conditions. Participants in the constant practice condition were asked to read aloud sentence stimuli with four Chinese characters. Participants in the blocked practice condition were asked to read aloud sentence stimuli with increasing sentence length, starting from sets of two characters to five characters. Participants in the random practice condition were asked to practice reading sentence stimuli of variable length from two to five characters presented in a random fashion. All training sessions took place in a soundtreated booth. Each participant was seated upright comfortably in a chair that was one meter away from a 17 inch computer monitor.

At the beginning of the training sessions, participants were introduced with the Labview-based training system on relaxed phonation ${ }^{15}$ (see Figure 1). The training system presented and prompted the participants to read aloud the sentence stimuli. During the sentence reading, the root-mean-square values of sEMG signals recorded at the participant's thyrohyoid site were automatically calculated by the system and presented as a numerical value on the computer screen as visual feedback for the participant. Participants were explained that the value displayed represented the laryngeal muscle activities. They were told that the larger the number, the greater the muscle activities and hence muscle tension. Each participant was informed of the objective about the training was to reduce the value by relaxing the neck muscles during the reading task. Throughout the training, participants were only allowed to view the value after the production of every two sentences for better motor learning as stated in the study by Cheung ${ }^{21}$. 
Post-training measurement (session 10). A delayed retention test using the training stimuli was conducted one week after the completion of the last training session. A transfer test was also carried out by reading aloud the untrained Cantonese passage "North Wind and the Sun" at their most comfortable pitch and loudness level. In the post-training measurement, no EMG visual feedback was given to the participants, but the muscle activities at orofacial and thyrohyoid sites were recorded for later analysis. Participants were required to complete the VAPP again.

\section{RESULTS}

\section{Effects of learning}

Motor learning was determined by comparing the sEMG voltages at the pre-training baseline with those at the post-training measurement (delayed retention test). A three-way within- and between- subjects ANOVA was used to determine the effects of learning. All the data sets were confirmed to be homogenous with the use of Levene's Test of Equality of Error Variances ${ }^{22}$. The root-mean-square sEMG voltage was the dependent variable. The within-subject variables included time (10 sessions across pre-training baseline measurement, training and post-training retention test) and electrode sites (orofacial and thyrohyoid sites). The between-subject variable included three practice conditions (i.e., constant, blocked and random practice conditions). Multivariate Pillai's Test of Significance, which is considered to be a robust test against violation of assumptions in multivariate tests ${ }^{23}$, was used to determine the main effects (time, electrode site, practice condition) and interaction effects of motor learning. An overall significance level of $p=0.05$ was set for statistical analysis. Table 2 lists the means and standard deviations of 
muscle tensions of three practice groups at orofacial and thyrohyoid sites across three measurement phases.

\section{$\underline{\text { Put Table } 2 \text { here }}$}

Time effect. Figure 2 shows the changes of muscle tension (pooled data) of all participants. Pillai's Trace ANOVA confirmed that the main effect of time was significant $[F(9,11)=3.11, p=0.05]$. The pooled data, across the three measurement phases, also demonstrated a decreasing trend in muscle tensions at both the orofacial and thyrohyoid sites across the three groups, indicating the presence of motor learning across time.

\section{$\underline{\text { Put Figure } 2 \text { here }}$}

Group effect (variable practice). There was no significant main effect of practice variability on laryngeal muscle relaxation $[F(2,18)=1.09, p>0.05]$.

Site effect. There was significant main effect of site $[F(1,19)=63.10, p=0.001]$. The thyrohyoid site demonstrated significant lower muscle tension than the orofacial site.

Interactions. None of the interactions reached a significant level at 0.05 criterion (site by group interaction: $F=0.22, p>0.05$; time by group interaction: $F=0.92, p>0.05$; site by time interaction: $F=0.34, p>0.05$; site by time by group interaction: $F=1.22, p>0.05$ ).

\section{$\underline{\text { Effects of generalization }}$}

Generalization effect was determined by comparing the results in the pre-training baseline and those in the transfer test. Table 3 lists the means and standard deviations of muscle 
tensions of the three practice groups at the orofacial and thyrohyoid sites across the two measurement phases (pre-training baseline and transfer test). Generalization of relaxed phonation skills to the untrained passage "North Wind and the Sun" was observed by comparing muscle tension values in the baseline measurement to those in the transfer test with the use of Friedman Test and Kruskal-Wallis Test as the data violated the normality assumptions with the use of Levene's Test of Equality of Error Variances ${ }^{22}$.

\section{Put Table 3 here}

Time effect. Figure 3 shows the changes of muscle tension (pooled data) of all participants. Friedman Test confirmed that the main effect of time was significant at both the thyrohyoid site [Friedman's Chi-Square $=21.81, d f=2, p=0.001]$ and the orofacial site [Friedman's Chi-Square $=8.67, d f=2, p=0.01]$. The results showed that a significant improvement was observed in the muscle tensions at both sites across baseline measurements and transfer test.

\section{Put Figure 3 here}

Group effect (variable practice). Kruskal-Wallis Test confirmed that main effect of practice variability was not significant on generalization in the laryngeal muscle relaxation. There was no significant main effect of practice conditions $(p>0.05)$ on laryngeal muscle relaxation at the two electrode sites across the two measurements (pretraining baseline and transfer test). 


\section{Voice Activity and Participation Profile (VAPP)}

Table 4 lists the statistical results of 14 VAPP scores in terms of $p$-values. Significant main time effect was observed in all the scores except the Participation Restriction Score on job and all the scores on social communication. Time-by-group interaction was confirmed on self-perceived severity of voice problems, Activity Limitation Scores (ALS) on job, Total ALS, and Total VAPP score.

\section{$\underline{\text { Put Table } 4 \text { here }}$}

\section{DISCUSSION}

The aim of the present study was to investigate the effects of practice variability on the learning of relaxed phonation in a group of dysphonic individuals. Participants were randomly assigned to one of the three groups of practice conditions, namely the constant, blocked and random practice conditions. The sEMG activities recorded at the participants' thyrohyoid site were provided to all participants as visual biofeedback during trainings. Results revealed a significant decreasing trend in muscle tensions across time at both the orofacial and thyrohyoid sites across the three groups, indicating motor learning has occurred. However, the present findings did not support the hypothesis that participants receiving random practice condition would demonstrate better motor learning on relaxed phonation when compared with participants receiving blocked or constant practice conditions. There was neither significant main effect nor interaction effect of practice variability on laryngeal muscle relaxation. Two possible explanations will be discussed below to account for the findings in the present study: the complexity and difficulty of the tasks and the methodological design of the relaxed phonation training used. 
$\mathrm{Li}$ and Wright ${ }^{24}$ commented that random practice was associated with higher cognitive demand than in blocked practice. Therefore, the random practice condition used in the present study was considered to be more difficult and it required more cognitive demand than blocked practice and constant practice. All dysphonic participants who took part in the present study did not receive any prior voice training in the past. Therefore, they were fresh to the relaxed phonation training and could be considered as "beginning learners" of this relaxed phonation skills. Therefore, lower levels of contextual interference would be better for beginning skill levels and higher levels of contextual interference would be better for more highly skilled individuals ${ }^{25}$. As mentioned above, all participants were considered as beginners for learning the relaxed phonation skills, so random practice might not be the optimal practice schedule for the participants to learn the relaxed phonation skills. Alternatively, a reduction in task difficulty (as in constant practice condition) early in practice might facilitate the participants' learning of the skill ${ }^{26}$.

The second possible explanation relates to the severity and duration of symptoms presented by the participants. The participants might have different severities of dysphonia and durations of symptoms. Colton, Casper and Leonard ${ }^{27}$ commented that the earlier the voice problem was identified, the more positive was the prognosis for improvement. As a result, the prognosis and improvement of each participant might be different, giving rise to a lack of difference in learning between practice conditions in the study. The inclusion of a larger sample size with better control of participants voice problem severity is warranted. 
Although the research findings did not indicate preference of any practice condition, the pooled data revealed that the sEMG levels at both orofacial and thyrohyoid sites were significantly reduced across time after the relaxed phonation training. The significant reduction in sEMG levels (hence muscle activities) indicated that participants had learnt to relax their vocal mechanism during the relaxed phonation training. Moreover, apart from the voice impairment perspective, the participants' self-perceived functional impacts of voice problems also revealed significant improvements. This was demonstrated by the significant decrease in the Total VAPP score, the subsection scores on the severity of voice problems, job, daily communication and self-perceived emotions at the end of the training. The relaxed vocal mechanism could have reduced the amount of limitations and restrictions participants encountered in carrying out voice activities. Therefore it seemed logical that participants perceived an improvement in their voice-related quality of life. To conclude, our findings show the relaxed phonation protocol is indeed successful at promoting participants to relax a hyperfunctional voice using any practice schedules. The findings on improved patients' self-perception of their voice problems further support the effectiveness of the relaxed phonation training for individuals with hyperfunctional voices. 


\section{ACKNOWLEDGEMENTS}

This study was supported in part by grants of the Research Grants Council of Hong Kong (HKU 7451/06H). The authors would like to express their gratitude to all participants who had participated in the present study. We are also grateful to Mr. Ronald Tse for his generous advice on the usage of the Labview Programme and the technical problems encountered throughout the study, as well as Ms. Mandy Ho for her support and assistance in subject recruitment. 


\section{REFERENCES}

1. Freeman M, Fawcus M. Voice disorders and their management. 3rd ed. London: Whurr Publishing, 2001.

2. Greene MCL, Mathieson L. The voice and its disorders (6th Ed). London: Whurr Publishers, 2001.

3. Boone DR, McFarlane SC, Von Berg SL. The voice and voice therapy. 7th ed. Boston: Pearson Education, Inc., 2005.

4. Schmidt RA, Lee TD. Motor control and learning: A behavioural emphasis. 3rd ed. Champaign, IL: Human Kinetics, 1999.

5. Magill RA. Motor learning: Concepts and applications. 5th ed. Boston, Mass: WCB McGraw-Hill, 1998.

6. Rose DJ. A multilevel approach to the study of motor control and learning. Boston: Allyn and Bacon, 1997.

7. Schmidt RA, Wrisberg CA. Motor learning and performance 2nd ed. Champaign, IL: Human Kinetics, 2000.

8. Shea JB, Morgan RL. Contextual interference effects on the acquisition, retention, and transfer of a motor skill. Journal of Experimental Psychology: Human Learning and Memory 1979;5:179-187.

9. Lee TD, Magill RA. Can forgetting facilitate skill acquisition? In: Goodman D, Wilberg RB, Franks IM, editors. Differing perspectives in motor learning, memory and control. Amsterdam: North-Holland, 1985.

10. Knock TR, Ballard KJ, Schmidt RA. Influence of order of stimulus presentation on speech motor learning: A principled approach to treatment for apraxia of speech. Aphasiology 2000;14(5-6):653-668. 
11. Yu GW-C. The Effect of Practice Distribution on the Training of Laryngeal Muscle Relaxation [Unpublished B.Sc. dissertation]. The University of Hong Kong, 2005.

12. Stemple JC, Weiler E, Whitehead W, Komray R. Electomyographic feedback training with patients exhibiting a hyperfunctional voice disorder. Laryngoscope 1980;90(3):471-476.

13. Andrews S, Warner J, Stewart R. EMG biofeedback and relaxation in the treatment of hyperfunctional dysphonia. British Journal of Disorders of Communication 1986;21:353-369.

14. Allen KD, Bernstein B, Chait DH. EMG biofeedback treatment of pediatric hyperfunctional dysphonia. Journal of Behaviour Therapy and Experimental Psychiatry 1991;22:97-101.

15. Ma EP-M, Wong AY-H, Tse RC-H. Self-practice training system on relaxed phonation: The University of Queensland / The University of Hong Kong, 2008.

16. Yiu EM-L, Verdolini K, Chow LP-Y. Electromyographic study of motor learning for a voice production task. Journal of Speech, Language and Hearing Research 2005;48:1254-1268.

17. Ho KC. A comparison of the 2,000 most frequently used Chinese characters found in three frequency counts carried out in China, Taiwan and Hong Kong. Hong Kong: Institute of Language in Education, 1993.

18. World Health Organization. International Classification of Functioning, Disability and Health (ICF). Geneva: World Health Organization, 2001.

19. Ma EP-M, Yiu EM-L, Verdolini-Abbott K. Application of the ICF in voice disorders. Seminars in Speech and Language 2007;28(4):343-350. 
20. Ma EP-M, Yiu EM-L. Voice activity and participation profile: Assessing the impact of voice disorders on daily activities. Journal of Speech, Language and Hearing Research 2001;44(3):511-524.

21. Cheung CPS. The effect of continuous versus fading feedback on laryngeal muscle relaxation learning [B.Sc. undergraduate dissertation]. The University of Hong Kong, 2004.

22. Pallant J. SPSS survival manual: A step by step guide to data analysis using SPSS for Windows (Version 12). 2nd ed. Maidenhead, Berkshire: Open University Press, 2005.

23. Coakes SJ, Steed LG. SPSS analysis without anguish: version 10.0 for Windows. Brisbane: Wiley, 2001.

24. Li Y, Wright DL. An assessment of the attention demands during random- and blocked-practice schedules. The Quarterly Journal of Experimental Psychology 2000;53A(2):591-606.

25. Guadagnoli MA, Lee TD. Challenge point: A framework for conceptualizing the effects of various practice conditions in motor learning. Journal of Motor Behaviour 2004;36(2):212-224.

26. Jones LL, French KE. Effects of contextual interference on acquisition and retention of three volleyball skills. Perceptual and Motor Skills 2007;105:883-890.

27. Colton RH, Casper JK, Leonard R. Understanding voice problems: A physiological perspective for diagnosis and treatment. 3rd ed. Philadelphia: Lippincott Williams \& Wilkins, 2006. 


\section{APPENDIX}

\section{Appendix 1a. Training stimulus list for Group 1 (Constant Practice)}

Block 1:

依個係的 依個係不 依個係有 依個係在 依個係了 依個係我 依個係爲

依個係這 依個係水 依個係起 依個係解 依個係果 依個係情 依個係每

依個係月 依個係教 依個係老 依個係片 依個係給 依個係男 依個係父

依個係卻 依個係談 依個係群

\section{Block 2:}

依個係的 依個係不 依個係有 依個係在 依個係了 依個係我 依個係爲 依個係這 依個係水 依個係起 依個係解 依個係果 依個係情 依個係每

依個係月 依個係教 依個係老 依個係片 依個係給 依個係男 依個係父

依個係卻 依個係談 依個係群

\section{Block 3:}

依個係的 依個係不 依個係有 依個係在 依個係了 依個係我 依個係爲

依個係這 依個係水 依個係起 依個係解 依個係果 依個係情 依個係每

依個係月 依個係教 依個係老 依個係片 依個係給 依個係男 依個係父

依個係卻 依個係談 依個係群

\section{Block 4:}

依個係的 依個係不 依個係有 依個係在 依個係了 依個係我 依個係爲

依個係這 依個係水 依個係起 依個係解 依個係果 依個係情 依個係每

依個係月 依個係教 依個係老 依個係片 依個係給 依個係男 依個係父

依個係卻 依個係談 依個係群

Note: Characters in bold and underline typeface are target characters 


\section{Appendix 1b. Training stimulus list for Group 2 (Blocked Practice)}

\section{Block 1:}

係的 係不 係有 係在 係了係我 係监 係這 係水 係起 係解 係果 係情 係每

係且 係教 係老 係片 係給 係男 係父 係卻 係談 係群

\section{Block 2:}

請講的 淸講不 請講有 淸講在 淸講了 請講我 淸講监 請講這 請講水 淸講起 請講解 請講果 請講情 淸講每 請講员 請講教 請講老 請講片 請講給 請講男 請講父 請講卻 請講談 請講群

\section{Block 3:}

依個係的 依個係不 依個係有 依個係在 依個係了 依個係我 依個係緺

依個係這 依個係水 依個係起 依個係解 依個係果 依個係情 依個係每

依個係月 依個係教 依個係老 依個係片 依個係給 依個係男 依個係父

依個係卻 依個係談 依個係群

\section{Block 4:}

依個字係的 依個字係不 依個字係有 依個字係在 依個字係了 依個字係我

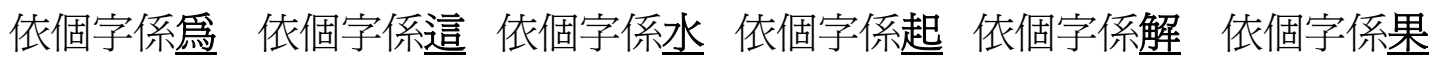
依個字係情 依個字係每 依個字係月 依個字係教 依個字係老 依個字係片 依個字係給 依個字係男 依個字係余 依個字係卻 依個字係談 依個字係群

Note: Characters in bold and underline typeface are target characters 


\section{Appendix 1c. Training stimulus list for Group 3 (Random Practice)}

Block 1:

依個係不 係我 請講情 依個係每 係群 依個字係水 請講月 係卻 請講了

依個字係父 請講教 依個字係這 依個係果 係男 依個字係談 依個係給

淸講监 係起 請講片 依個字係老 依個係解 係在 請講的 依個係有

\section{Block 2:}

係水 依個係老 係且 依個係我 係果 依個字係有 依個係卻 係不 依個字係給 依個係教 請講父 依個字係解 係情 依個字係在 請講起 係了 淸講群

依個係爲 係談 依個字係的 請講這 係每 依個係男 依個字係片

Block 3:

請講果 係教 依個係談 依個字係起 依個係片 依個字係月 依個係群 依個字係男 依個係在 請講解 係的 依個字係每 依個係水 依個字係我

請講有 依個字係不 請講老 依個係父 依個字係临 依個係了 請講給 依個係這 請講卻 依個字係情

\section{Block 4:}

請講在 依個係情 係解 淸講水 依個字係了 係爲 請講談 依個字係果

依個係的 請講每 係父 請講男 依個字係教 係給 依個係起 係老 請講不

依個字係卻 係片 依個係旦 係有 請講我 依個字係群 係這

Note: Characters in bold and underline typeface are target characters 
Table 1. Target characters used in Yiu, Verdolini and Chow ${ }^{16}$

\begin{tabular}{|c|c|c|c|c|c|}
\hline $\begin{array}{l}\text { Target } \\
\text { Stimuli }\end{array}$ & $\begin{array}{c}\text { IPA } \\
\text { Symbol }\end{array}$ & $\begin{array}{c}\text { Order of } \\
\text { frequency } \\
\text { based on Ho } \\
\text { (1993) }\end{array}$ & $\begin{array}{l}\text { Target } \\
\text { Stimuli }\end{array}$ & $\begin{array}{c}\text { IPA } \\
\text { Symbol }\end{array}$ & $\begin{array}{c}\text { Order of } \\
\text { frequency } \\
\text { based on Ho } \\
\text { (1993) }\end{array}$ \\
\hline 1. 的 & tik55 & 1 & 13. 情 & ts $^{\text {h }} i_{21}$ & 176 \\
\hline 2. 不 & pet $_{55}$ & 4 & 14. 每 & mui23 $_{23}$ & 196 \\
\hline 3. 有 & $\mathrm{jeu}_{23}$ & 5 & 15. 月 & jyt $_{22}$ & 216 \\
\hline 4. 在 & tsoi 22 & 6 & 16. 教 & $\mathrm{Kau}_{33}$ & 231 \\
\hline 5. 了 & $\operatorname{liu}_{23}$ & 7 & 17. 老 & $\operatorname{lou}_{23}$ & 239 \\
\hline 6. 我 & $\mathrm{y}_{23}$ & 9 & 18. 片 & $\mathrm{p}^{\mathrm{h}_{\text {in }}}{ }_{33}$ & 246 \\
\hline 7. 爲 & Wei 22 & 10 & 19. 給 & $\mathrm{k}^{\mathrm{h}} \mathrm{ep} 55$ & 259 \\
\hline 8. 這 & ts $\varepsilon_{35}$ & 11 & 20. 男 & $\operatorname{nam}_{21}$ & 328 \\
\hline 9. 水 & sœy35 & 75 & 21. 父 & $\mathrm{fu}_{22}$ & 332 \\
\hline 10. 起 & heis5 & 104 & 22. 卻 & $\mathrm{k}^{\mathrm{h}} \mathrm{k}_{33}$ & 461 \\
\hline 11. 解 & $\mathrm{kai}_{35}$ & 117 & 23. 談 & $\mathrm{t}^{\mathrm{h}} \mathrm{am}_{21}$ & 464 \\
\hline 12. 果 & $\mathrm{kWO}_{35}$ & 171 & 24. 群 & $\mathrm{kW}^{\mathrm{h}} \mathrm{en}_{21}$ & 716 \\
\hline
\end{tabular}

Note: The selection of target words was based on its order of frequency ${ }^{17}$ 
Table 2. Means (standard deviations) of muscle tension in microvolt $(\mu \mathrm{V})$ for constant, blocked and random practice conditions across three measurement phases

\begin{tabular}{llllllllll}
\hline Baseline & \multicolumn{1}{c}{ Training sessions } & & Retention \\
\hline & 1 & 2 & 3 & 4 & 5 & 6 & 7 & 8 & \\
\hline
\end{tabular}

CONSTANT PRACTICE

\begin{tabular}{lccccccccccc} 
Pooled data & $\mathbf{2 8 . 8 9}$ & $\mathbf{2 5 . 8 5}$ & $\mathbf{2 2 . 2 4}$ & $\mathbf{2 3 . 4 4}$ & $\mathbf{2 2 . 8 8}$ & $\mathbf{2 4 . 3 0}$ & $\mathbf{2 4 . 3 5}$ & $\mathbf{2 3 . 2 2}$ & $\mathbf{2 4 . 3 5}$ & $\mathbf{2 2 . 7 5}$ \\
Orofacial site & 37.53 & 34.18 & 27.24 & 30.85 & 30.19 & 32.82 & 33.75 & 31.04 & 34.11 & 30.78 \\
& $(9.03)$ & $(14.35)$ & $(7.39)$ & $(8.90)$ & $(7.48)$ & $(13.28)$ & $(18.26$ & $(7.87)$ & $(5.92)$ & $(8.76)$ \\
Thyrohyoid site & 20.24 & 17.52 & 17.23 & 16.03 & 15.56 & 15.77 & 14.95 & 15.40 & 14.58 & 14.71 \\
& $(4.11)$ & $(4.68)$ & $(3.70)$ & $(4.20)$ & $(4.40)$ & $(3.99)$ & $(3.17)$ & $(4.23)$ & $(3.06)$ & $(3.82)$ \\
\hline
\end{tabular}

BLOCKED PRACTICE

$\begin{array}{lllllllllll}\text { Pooled data } & 25.56 & 25.63 & 24.05 & 24.94 & 22.86 & 22.13 & 22.25 & 20.05 & 20.18 & 21.66\end{array}$

$\begin{array}{lllllllllll}\text { Orofacial site } & 34.13 & 34.62 & 31.79 & 33.75 & 30.21 & 28.81 & 30.32 & 27.08 & 27.34 & 30.98\end{array}$

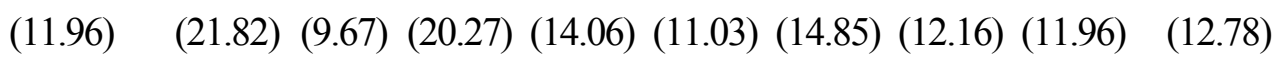

$\begin{array}{lllllllllll}\text { Thyrohyoid site } & 16.98 & 16.63 & 16.30 & 16.12 & 15.50 & 15.45 & 14.18 & 13.01 & 13.01 & 12.33\end{array}$

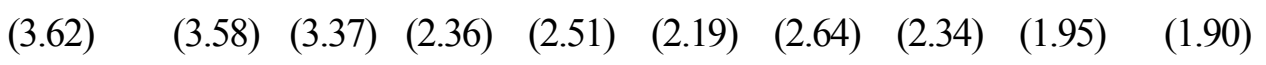

\section{RANDOM PRACTICE}

\begin{tabular}{lcccccccccc} 
Pooled data & $\mathbf{2 6 . 9 6}$ & $\mathbf{2 6 . 6 2}$ & $\mathbf{2 3 . 6 5}$ & $\mathbf{2 5 . 4 4}$ & $\mathbf{2 3 . 1 3}$ & $\mathbf{2 3 . 5 8}$ & $\mathbf{2 3 . 4 3}$ & $\mathbf{2 2 . 0 4}$ & $\mathbf{2 0 . 9 3}$ & $\mathbf{2 1 . 9 3}$ \\
Orofacial site & 32.81 & 31.83 & 29.92 & 33.20 & 29.58 & 30.55 & 30.97 & 29.25 & 27.36 & 28.86 \\
& $(15.19)$ & $(10.64)$ & $(6.79)$ & $(11.62)$ & $(6.58)$ & $(8.46)$ & $(10.20)$ & $(7.07)$ & $(9.06)$ & $(9.82)$ \\
Thyrohyoid site & 21.10 & 21.41 & 17.38 & 17.67 & 16.68 & 16.61 & 15.88 & 14.83 & 14.50 & 15.00 \\
& $(3.80)$ & $(3.80)$ & $(3.61)$ & $(2.84)$ & $(2.35)$ & $(1.47)$ & $(1.88)$ & $(2.65)$ & $(2.96)$ & $(3.26)$ \\
\hline
\end{tabular}


Table 3. Means (standard deviation) of muscle tension in microvolt $(\mu \mathrm{V})$ for constant, blocked and random practice conditions at transfer test

\section{Pre-training baseline Transfer test}

\section{CONSTANT PRACTICE}

Pooled data

Orofacial site

Thyrohyoid site
34.72

$44.87(15.71)$

$24.56(9.59)$
26.61

$37.13(5.59)$

$16.08(4.62)$

\section{BLOCKED PRACTICE}

Pooled data

Orofacial site

Thyrohyoid site
34.83

$52.18(32.96)$

$17.48(4.23)$

\subsection{5}

$36.55(14.01)$

$13.74(3.94)$

\section{RANDOM PRACTICE}

Pooled data

Orofacial site

Thyrohyoid site
33.78

$43.21(13.87)$

$24.34(3.79)$
25.46

$36.03(10.47)$

$14.88(2.28)$ 
Table 4. Statistical p-value (main effect of time and interaction effect of group by time) on the Voice Activity and Participation Profile (VAPP) scores

\begin{tabular}{lll}
\hline VAPP Scores & Time effect & Time by group effect
\end{tabular}

\begin{tabular}{lll}
\hline Self-perceived severity of voice problems & $0.001^{* *}$ & $0.03^{*}$
\end{tabular}

Job

Section Scores

$0.002^{* *}$

n.s.

Activity Limitation Score (ALS)

$0.0001^{* *}$

$0.03^{*}$

Participation Restriction Score (PRS)

n.s.

n.s.

\section{Daily communication}

Section Scores

$0.002 * *$

$0.03^{*}$

ALS

$0.005^{* *}$

$0.02 *$

PRS

$0.003^{* *}$

n.s.

\section{Social communication}

Section Score

n.s.

n.s.

ALS

n.s.

n.s.

PRS

n.s.

n.s.

\section{Emotions}

Section Score

$0.02 *$

n.s.

Total VAPP Score

$0.002^{* *}$

$0.04^{*}$

Total ALS Score

$0.001 * *$

$0.008^{* *}$

Total PRS Score

$0.006^{* *}$

n.s.

Note: $\quad *=$ Significant at 0.05 level; $* *=$ Significant at 0.01 level

n.s. $=$ Not significant; No significant group main effect was obtained 


\section{FIGURE CAPTION}

Figure 1. Self-practice training system on relaxed phonation ${ }^{15}$

Figure 2. Changes of muscle tension of all participants across ten measurements

Figure 3. Changes of muscle tension of all participants across pre-training baselines and transfer test 


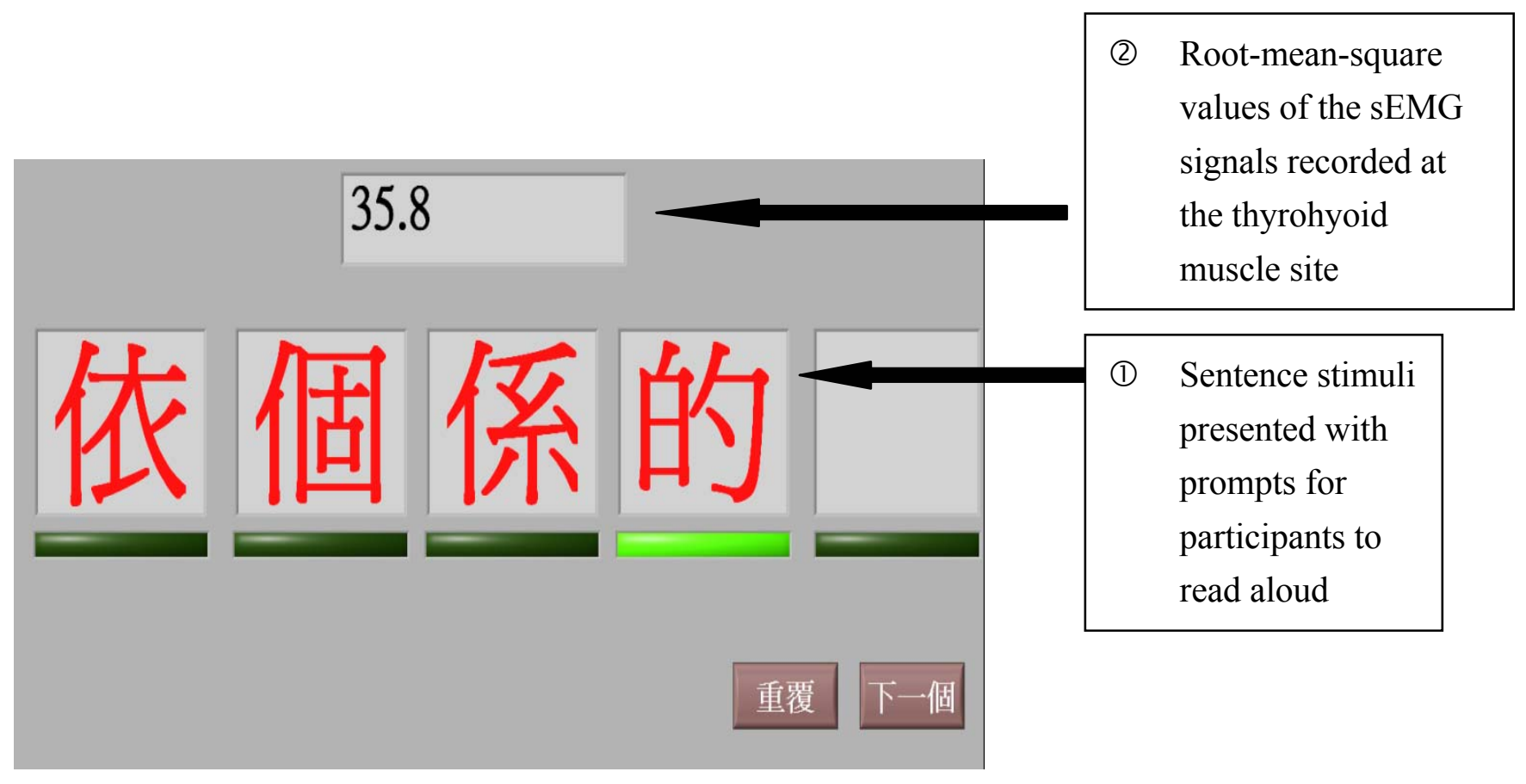

Figure 1. Self-practice training system on relaxed phonation ${ }^{15}$ 


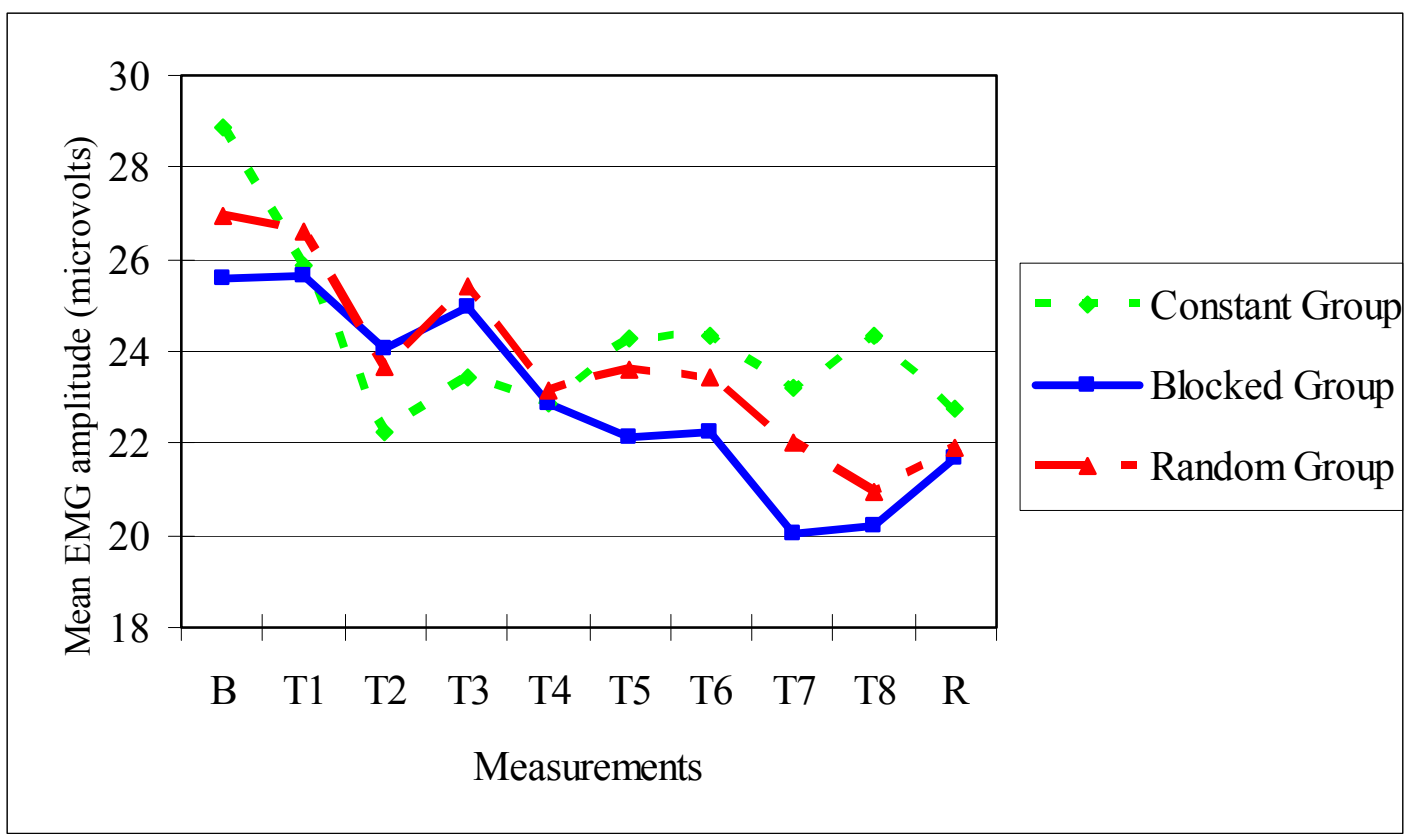

Key: $\mathrm{B}-$ Pre-training baseline $\quad \mathrm{T}-$ Training $\mathrm{R}$-Post-training (retention test)

Figure 2. Changes of muscle tension of all participants across the 10 measurements 


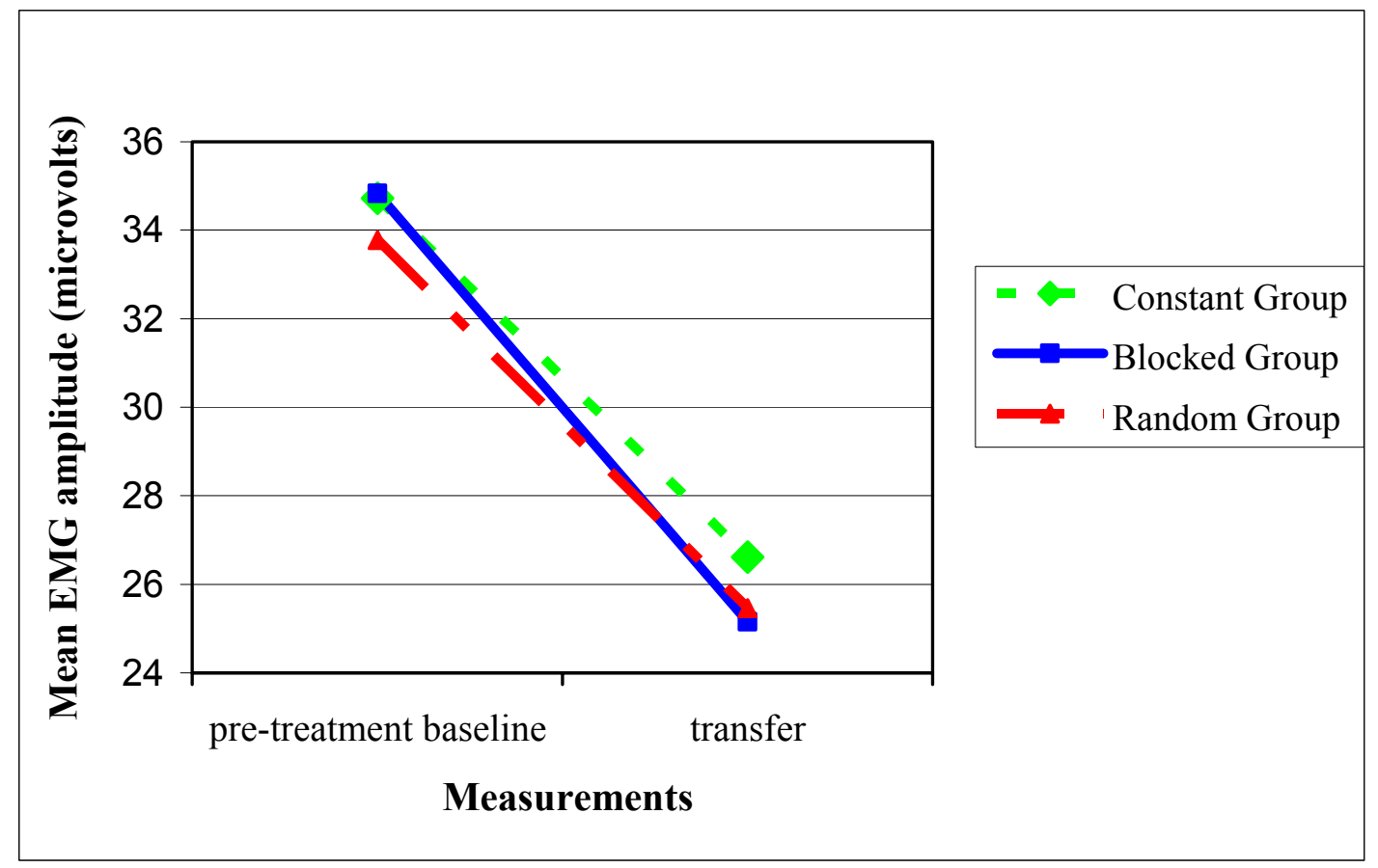

Figure 3. Changes of muscle tension of all participants across pre-training baselines and transfer test 